\section{Human Resource \\ Management Challenges in a Developing Economy}

\author{
Sunia Vosikata \\ Graduate School of Business, The University of \\ the South Pacific, Suva, Fiji
}

\section{Synonyms}

HRM practice; Human resources management; Public service reform; Social capital; Western HRM practice

\section{Definition}

Networking The action or process of interacting with others to exchange information and develop professional or social contacts.

Public Government and all publicly Sector controlled or funded entities that deliver programs, goods, and services.

Public A service intended to serve all

Service members of a community. It is usually provided by the government to people within its jurisdiction, either directly (through the public sector) or by financing provision of services.
Itaukei Native or indigenous Fijian.

Indo-Fijian Are Fijian citizens of fully or partially south Asian descent, including descendants who trace their heritage from various regions of the Indian subcontinent.

\section{Introduction}

The key HRM challenges facing developing economies today vary in accordance with its respective doctrines for survival and good governance, taking into account its political and economic environment. In acknowledging the known HRM challenges, the foregoing will focus on unknowns and emerging challenges in the Fiji Public Service (FPS). Vallance (1996) highlighted several known challenges and these included brain drain; poor education quality within the HR pool; and lack of manpower planning. While these known challenges have intensified through the postindependence and post-republic era in Fiji, other unknown HRM challenges are presented in text and include: difficulty of transferring and utilization of Western HRM practices; pressures for reform on the public service from donor agencies and their stakeholders; and the need to change the mindset of public servants (Hewitt et al. 2002). These unknowns provide substantive contributions to develop the HRM literature for the FPS in view of the challenges they impose on HRM. These critical insights have been formulated as the 
basis in understanding the contemporary outlay that has shaped HRM within the FPS.

\section{The Model and Rationality}

Building and understanding a well-grounded HRM theoretical framework are crucial to guide the management of HRM through its varying functions. It is absolutely essential that FPS managers are not only guided by a relevant theoretical framework to incorporate and instill elements of rationality to improve the accuracy of decisionmaking and strategy formulation, but also must understand the preconditions, merits, and logic behind the predictions of the model and its framework (Vosikata and Faifua 2012). Against the Pacific Islands (PI) social capital backdrop that provides the contextual basis, the critical alignment of the various HRM challenges as against the practice of the same in view of HRM policy development and application is presented. The accumulated social capital in Fiji from the different ethnic groups provided the basis for the inception of social subsystems that formed networking ties.

The impact of globalization has influenced HRM in developing nations like Fiji, and public service managers are mandated by the state and other key stakeholders to modify the methodology of operations and service delivery. In his study, Holden (2002) stated that this issue, together with the serious economic downturn of the 1990s particularly among developing economies, caused many to abandon regulatory state measures for more liberal economic policies. In the process, the subsequent environmental influences hinder HRM theoretical development in developing nations and the consequences are severely felt. The vulnerability of these countries' policy infrastructure is unable to withstand the robustness of the market. HRM in the FPS can be classified as a "cross-cultural HRM," where multicultural phenomena have been spinning diverse networking intricacies through the social, political, and economic environment and indirectly reinforcing their stronghold and status on HRM policies and its application.
It is important to conceptualize the ways in which HRM ideologies confront the social context in a developing nation, particularly how they are embraced and adopted. Poole (1982) established the effective harnessing of HRM as the discipline base for his theory, which provides the theoretical framework for his study. He linked the theoretical constructs to the research design by highlighting key HR variables, grouping them and operationalizing them to form two key research questions. Firstly, what are some of the general forces that affect the personnel function in organizations, and secondly, what are some ways in which HRM may be different in "emergent" countries from other developed nations? In that context, presenting HRM challenges in developing economies (Pacific Island Countries PICs) is substantial since these microstates have a unique social context.

Three major challenges depicted in Fig. 1 represent the core theories in view of how HRM ideologies have been challenged in developing economies, including Fiji.

\section{Mimicking of Western HRM Practices}

The Western HRM model was not brought into developing economies public sector institutions (e.g., the FPS), as a result of comprehensive needs assessment backed by a theoretical framework to guide the application of these theories. Rather, the rationale for their implementation could be aligned with Mellahi and Frynas (2003)'s findings which informed that in view of their fragility, developing countries had no alternative but to accept consultative governance infrastructure and policy assistance through aid from donor agencies, particularly from developed economies. In this context, reform packages for developing and underdeveloped nations were always conducted on a reactive rather than a proactive basis, and the major pre-conditions were the change in government and the interests of government key stakeholders in the private sectors and corporatized institutions. Consequently, the forces behind these changes emanated through the obligation of democratically elected governments to their electorates through their political 


\section{HRM challenges facing Fiji Public Service}

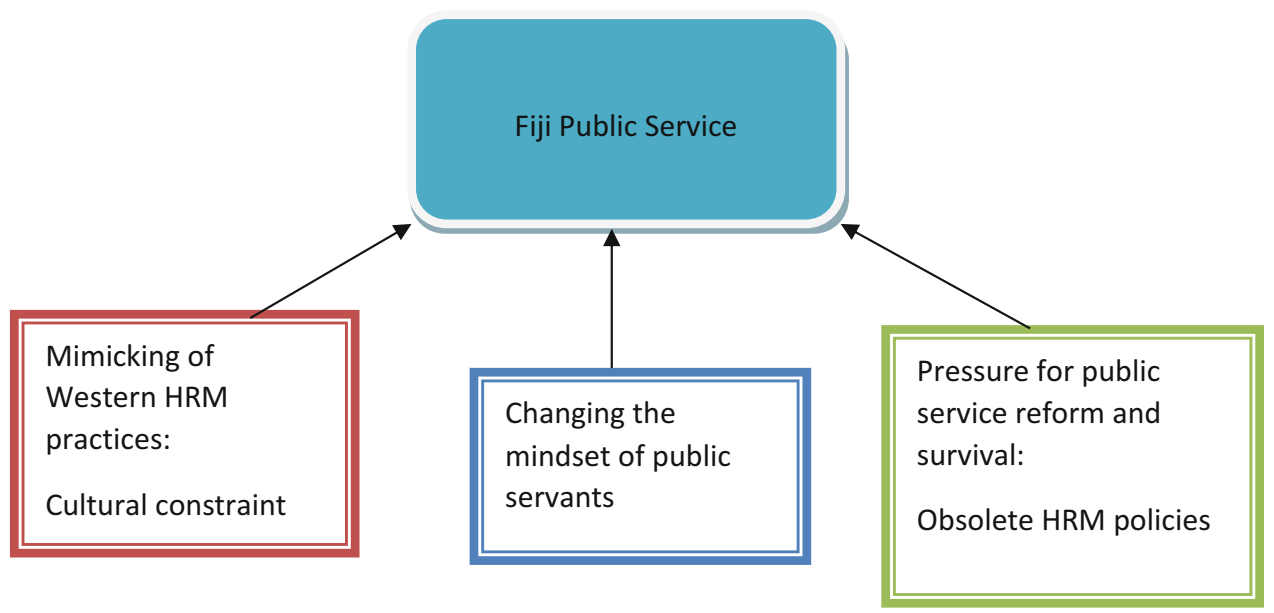

Human Resource Management Challenges in a Developing Economy, Fig. 1 HRM challenges facing Fiji Public Service

manifestos, which indirectly accumulated unnecessary mileage that pressurized the bureaucracy and state institutions.

Fiji became a fully sovereign and independent nation within the Commonwealth on 10 October 1970. Fiji was a parliamentary democracy for 17 years after independence, and during that period Ratu Sir Kamisese Mara and the Alliance Party dominated political life. However, ethnic tensions between the two major races resulted in a series of military coups $(1987,2000$, and 2006) deducing a social situation whereby public service institutions have remained troubled and fractured. Because of that, the developmental status of the HRM framework within the FPS was continually bombarded with unnecessary intrusion by key stakeholders of government. The unnecessary intrusion destabilized any rationality in formulating the HRM framework; hence mimicking Western and readymade HRM practices was the only way out. In conducting a study on the FPS reforms, Sarker and Pathak (2003) found that the FPS was not ready because social, political, and economic objectives were often conflicting. Thus, the aggressive determination of the social and political networking institutions to attain and assume control of the management of the state and its affairs always took a lead over sound economic management.

As a result of the political developments of 1987 and the birth of the Republic of Fiji, the immense pressure to continue and uphold efficiency and effectiveness to operate the FPS was eminent. Considering the situation, managers in the FPS desperately searched for new ready-toimplement HRM concepts. This was not done because their previous practices and policies had become obsolete and inadequate in the new corporate and public sector environment, but was out of necessity in order to manage and operate the public service in the new republic, considering its social and political contexts.

\section{Cultural Constraints}

The national culture of a nation often provides the national temperament, which influences HRM 
policies. In some very collectivist and familyoriented societies, selecting someone you know is often a norm and considered ethical. In their study of the Iranian public and private sectors, Cassar and Bezzina confirmed that "a distinctive challenge facing the Iranian public sector human resources (HR) selection programme is nepotism or hiring someone who is known to someone else in the organization" (2005: p. 165). They found that this is due to the Iranian national culture of being family oriented and distrusting outsiders. The assumption is that a known person will be more committed and loyal to the organization than a complete stranger.

Mimicking Western HRM practices in the Fiji social context was not easy, as cultural constraints often infiltrate the management of the public services. However, given the socioeconomic and legal environment for the period (1987-2006), it was the ideal policy initiative. This was because of the inherent difficulty in formulating a conducive HRM framework suited to a developing nation's public sector institution operating under such environment. An additional constraint for the FPS would be the difficulty in transferring HRM practices into a work culture consisting of public servants made up predominantly of Itaukei who were used to their communal family-oriented framework and Indo-Fijians with their individualistic cultural set up (Nayacakalou 1975). The political and social environment of Fiji, particularly after the developments in 1987, reinforced segregation of the mainstream races, building a nationalistic culture, which infiltrated HRM policies of the FPS.

\section{Pressure for Public Service Reform and Survival}

The impact of mimicking Western HRM practices as a challenge on HRM within the FPS is complimented with the immense pressure for reform and survival for the Republic of Fiji and its public service. In that regard, mimicking Western HR practices as a policy choice has been a challenge for developing economies. However, it is crucial in managing public service institutions and in stabilizing the operations in view of political, social, and economic uncertainties. In their research on the Algerian civil service, Mellahi and Frynas found that "mimicking western HRM practices in an alien social context are often ineffective and the objective for such integration into public services are often vigorously scrutinised by stakeholders" (2003: p. 77). This is because of the inherent difficulty in transferring HRM ideologies between different cultures and the inability of Algerian managers to understand the potential problems that might be created by applying western HRM practices in Algeria (Mellahi and Frynas 2003). In that regard, expectations for the performance of public sector institutions from key stakeholders may override any rationality in the application of HRM policies. Hence, performance expectations may exert pressure for public service reform and survival.

\section{Obsolete HRM Policies}

For Fiji, pressures for reform also emanate from stakeholder claims that the public enterprises were operating at unacceptably low levels of efficiency and effectiveness. These stakeholders include internal private sector institutions and external financiers, including certain leading developed economies and their financiers. Some of the reasons identified for this included a lack of accountability, overstaffing, corruption, and cronyism (Department of Public Enterprises 1998). Mellahi and Frynas also confirmed that "managers in the civil service have desperately searched for new ready-to-implement management concepts as their previous practices have become obsolete and inadequate in the new business environment" (2003: p. 75). They found that these managers hoped that such adoption would enhance their effectiveness and give them a fighting chance in the fiercely competitive global markets.

External donor agencies, particularly the International Monetary Fund (IMF), World Bank, and the Asian Development Bank (ADB), have also been exerting pressure for reforms and have played a key role in public service reforms in Fiji. This pressure-cooker situation capitulates 
FPS managers to implement reforms dictated by change agents, and policy structures of these reforms included the application of Western HRM practices, which is not conducive to the developmental potential of HRM policy instruments in developing nations including Fiji. One has to wonder whether they were actually being coerced by the "change agents" to adopt public service reforms through HRM infrastructural and policy changes. On that note, PI countries' public service reform patterns all had the same unique framework whereby the donor agencies dictated and indirectly controlled the reform processes (Vallance 1996). In Fiji, for example, at the time of the FPS's establishment, Western democracies including Australia and New Zealand were leading the "charge" for efficiency, expediency, and managerial autonomy through decentralization of the public services (Fiji Government Gazette no. 1, 1874). Fiji and other PIC countries have neither the resources nor the flexibility to transform their public services quickly or to keep pace with global trends in public service management. The outcome has made PIC countries over-reliant on the developed economies within Oceania, hence reinforcing their status as micro-states.

Political and economic instability in Fiji also exacerbated the situation, hindering the rationality of public service reform initiatives. On that note, FPS managers and policy makers had a key role in influencing HRM legislation, particularly HR selection and decisions. Fiji neither had the resources nor the flexibility to transform its public services quickly or to keep pace with global trends in public management. The scenario was exacerbated in the period 1987-2006 with unnecessary intervention in its democratic processes and systems of governance. The outcome made Fiji over-reliant on the developed economies within Oceania and the developed world who continued to assert their status as the life-saver of Pacific Islands (PI) microstates. This over-reliance created a norm over time for these PIC including Fiji, whereby reputable institutions like the United Nations, World Bank, and others classify them as developing or under-developed nations. As evident in many SPI countries, including Fiji, the above-mentioned donor agencies have been permanently set up within developing economies to manage the aid bandwagon in its many forms, from infrastructural to HR development. Further, the public service reforms were often initiated through a tripartite arrangement where political mileage was often prioritized against the rationality of incorporating the desired economic objective (Sarker and Pathak 2003).

\section{Changing Mindsets of Public Servants}

Public service reforms were often initiated in developing economies through a tripartite arrangement where social, political, and economic mileage were prioritized as against incorporating desired HRM practices to improve performance. Cassar and Bezzina highlighted that "the structural and operational changes in the Maltese public service were spearheaded through the European Union (EU), due to Malta's accession to the EU" (2005: p. 213). Further, they also stated that it is important to note that under the supervision of the EU, the Maltese Public Service Reform Commission Report (MPSCR) mandate was primarily to execute structural and policy changes. The attempt to change old mindsets (Hewitt et al. 2002) was relatively ignored, except for retraining recommendations. This is "considering a work force environment which is characterised by: relatively small-scale market conditions, community oriented business giving rise to a clan mode of organising work" as found by Ouchi (1980), and "dominant cultural norm of consensus and tradition ingrained in traditional values and beliefs" (Baldacchino 1999). This societal set-up is similar to many developing nations in the Pacific, including Fiji. Further, Cassar and Bezzina found that Malta although in a transitional state, "still operates an institutionalised employment relationship based on collective agreements in which many conditions of employment are regulated by powerful societal systems and preset by national legislations and networking" (2005: p. 207). The critical lesson for public service organizations in developing nations from the Maltese civil service study is that "people must change before institutions can." 
The domination of culture over HRM ideology and the tensions between the competing social capital groups within the FPS have resulted in public servants clinging to their own social group mindset. In this regard, public servant's mindset needs to be changed to fully embrace newer ideologies, good governance, and HRM concepts that improve and sustain worker performance. The major issue contributing to the current mindset of Fiji public servants stems from the social environment through culturally developed social capital.

In view of the above mentioned, two critical assumptions need to be presented. Firstly, the belief and traditional obligations of Itaukei that social capital is inherited and must be owned for life (Ravuvu 1987), and the ontology regarding economic prowess from Indo-Fijians that social capital is acquired through savings and hard work, hence their identity must be formally recognized by the state legalizing ownership and status. When entering the FPS, public servants from these two dominant ethnic groups transfer these beliefs into the FPS through their ethnic groups' social capital ideologies and networking; hence, mindsets are preconditioned by the culturally ingrained phenomena.

\section{Conclusion}

The stated constructs have provided the leeway in challenging HRM in a developing nation context where organizations and government institutions are attempting to implement Western HRM practices. The theoretical framework has the potential to expand knowledge on the challenges to contemporary ideologies in HRM poised by the vulnerability of developing economies and microstates. Since gaining independence from Britain in 1970, Fiji has experienced a period of military coups d'état that have radically changed the government and the bureaucracy. The ramification of this event on HRM within the FPS has been severe and has influenced the HR competency databank of the FPS. Vallance found that through emigration and brain drain, "chronic shortages of skilled staff characterise the public service sectors of many Pacific Island countries including Western Samoa, Vanuatu, Solomon Islands, Tonga and Kiribati" (1996: p. 93). Compared to other PI countries, the population of Fiji has recorded a much more diverse ethnicity. However, the coup d'état era alone cannot be blamed for the HRM constraints and associated challenges, as the root cause of instability lies deeply embedded within the societal environment of Fiji. The vulnerability of many PI countries has also affected their ability to operate their bureaucracies and handsomely compensate public servants to operate the needed competency level for each public service function. This has posed a critical challenge for HRM in the FPS, hence it is forced to rely heavily on others.

\section{Cross-References}

\author{
- Human Resource Planning \\ - Human Resource Productivity \\ $\checkmark$ Pay Reform \\ > Performance Evaluation \\ - Strategic Management of Public Employees
}

\section{References}

Baldacchino G (1999) Small business in small island nations: a case study from Fiji. J Small Bus Manag 37(4):80-84

Bourdieu P (1980) Social capital. Acts Soc Sci Res 31:2-3

Cassar V, Bezzina C (2005) People must change before institutions can: a model addressing the challenge from administering to managing the Maltese Public Service. Public Adm Dev 25(3):205-215

Department of Public Enterprise Report (1998)

Fiji Royal Gazette, no. 1, 1874

Hewitt T, Wangwe S, Wield D (2002) Seeing eye to eye: organizational behaviour, brokering and building trust in Tanzania. Public Adm Dev 22:97-108

Holden N (2002) Cross-cultural management: a knowledge management perspective. Prentice Hall, Harlow

Mellahi K, Frynas J (2003) An exploratory study into the applicability of western HRM practices in developing countries: an Algerian case study. Int J Commer Manag 13(1):61-80

Nayacakalou RN (1975) The Fijian system of kinship and marriage. J Polyn Soc 64(1):44-55

Ouchi WG (1980) Markets, bureaucracies, and clans. Adm Sci Q 25:129-141 
Poole MJF (1982) Personnel management in third world countries. Pers Rev 11(4):20

Ravuvu A (1987) The Fijian ethos. Institute of Pacific Studies, University of the South Pacific, Suva

Sarker AE, Pathak RD (2003) Public enterprise reform in Fiji Islands. Public Organ Rev 3(1):55-75
Vallance S (1996) The human resource crises in Fiji's public sector: trouble in paradise? Public Adm Dev 16(1):91-103

Vosikata S, Faifua D (2012) HR selection distortions: a theoretical framework for the Fiji Public Service. J US-China Public Adm 9(7):775-790 